Letter

\title{
On the Land-Sea Contrast in the Surface Solar Radiation (SSR) in the Baltic Region
}

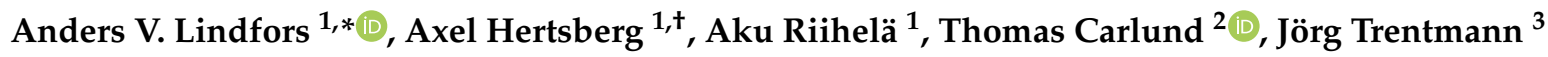 \\ and Richard Müller ${ }^{3}$ \\ 1 Finnish Meteorological Institute, P.O. Box 503, 00101 Helsinki, Finland; axel.hertsberg@gmail.com (A.H.); \\ aku.riihela@fmi.fi (A.R.) \\ 2 Swedish Meteorological and Hydrological Institute, 60176 Norrköping, Sweden; thomas.carlund@smhi.se \\ 3 Deutsche Wetterdienst, 63067 Offenbach, Germany; joerg.trentmann@dwd.de (J.T.); \\ richard.mueller@dwd.de (R.M.) \\ * Correspondence: anders.lindfors@fmi.fi \\ † Current address: Eniram Oy, 00101 Helsinki, Finland.
}

Received: 28 September 2020; Accepted: 21 October 2020; Published: 26 October 2020

check for updates

\begin{abstract}
The climatological surface solar radiation (SSR; also called global radiation), which is largely dependent on cloud conditions, is an important indicator of the solar energy production potential. In the Baltic area, previous studies have indicated lower cloud amounts over seas than over land, in particular during the summer. However, the existing literature on the SSR climate or how it translates into solar energy potential has not paid much attention to how the SSR behaves quantitatively in relation to the coastline. In this paper, we have studied the climatological land-sea contrast of the SSR over the Baltic area. For this, we used two satellite climate data records, CLARA-A2 and SARAH-2, together with a coastline data base and ground-based pyranometer measurements of the SSR. We analyzed the behaviour of the climatological mean SSR over the period 2003-2013 as a function of the distance to the coastline. The results show that off-shore locations on average receive higher SSR than inland areas and that the land-sea contrast in the SSR is strongest during the summer. Furthermore, the land-sea contrast in the summer time SSR exhibits similar behavior in various parts of the Baltic. For CLARA-A2, which shows better agreement with the ground-based measurements than SARAH-2, the annual SSR is $8 \%$ higher $20 \mathrm{~km}$ off the coastline than $20 \mathrm{~km}$ inland. For summer, i.e., June-August, this difference is $10 \%$. The observed land-sea contrast in the SSR is further shown to correspond closely to the behavior of clouds. Here, convective clouds play an important role as they tend to form over inland areas rather than over the seas during the summer part of the year.
\end{abstract}

Keywords: surface solar radiation; global radiation; solar energy; satellite; Baltic area; coastline; cloud; convection; climate

\section{Introduction}

Globally, clouds are more prevalent over seas than over land [1,2]. Over mid-to-high latitudes in the Northern Hemisphere, however, surface-based synoptic weather reports show higher cloud amount over land than over seas [3]. In Sweden, the land-sea contrast in cloud behavior was studied already by Ångström in 1928 [4]. He analyzed measurements of bright sunshine duration across the Swedish west coast and found that Vinga, a lighthouse in the outermost archipelago, had $11 \%$ more sunshine than Kålltorp, which is located slightly east of the central parts of Gothenburg. The distance between these two locations is ca $27 \mathrm{~km}$. Angström further referred to similar results on the Swedish east coast reported by J. Westman. An early sunshine climatology over Finland, presented by Lunelund 
in 1941 [5], also indicates a land-sea contrast in the duration of bright sunshine, with relatively high values along the coastline and in the archipelago.

More recently, the subject was studied by Karlsson [6], who created a satellite-based Scandinavian cloud climatology using Advanced Very High Resolution Radiometer (AVHRR) measurements. He found that the Baltic sea is less cloudy than the surrounding inland areas from April to September, and that this land-sea contrast in the summer time cloudiness is most pronounced during the afternoon, indicating a role of convective clouds forming over the inland areas, caused by solar heating of the surface. In winter, on the other hand, Karlsson [6] found the cloudiness in Scandinavia to be generally rather high, without any distinct geographical feature.

These general features of the cloud climate do, of course, have an effect on the surface solar radiation (SSR; also called global radiation) and thereby also on the solar energy resource. Thus, a land-sea contrast in the climatological SSR can be expected, with higher radiation over the sea than over land. Indeed, Persson [7], who studied the solar radiation climate of Sweden, found that the SSR in Visby (Gotland) was 12\% higher than at a location of similar latitude, but located inland. Apart from this, however, existing literature on the SSR climate (e.g., [8]) or how it translates into solar energy potential over Europe (e.g., [9]) has not paid much attention to how the land-sea contrast in the SSR behaves quantitatively. Therefore, from the perspective of solar resource assessment, it would be important to have better information on the SSR climatology in coastal areas.

The aim of this paper is to quantify the land-sea contrast in the SSR climate over the Baltic Sea and its surrounding areas. For this, we used two different satellite-retrieved SSR data sets from EUMETSAT's Climate Monitoring Satellite Application Facility (CM SAF), a coastline data base and ground-based measurements of the SSR from the Swedish and Finnish networks.

\section{Materials and Methods}

\subsection{Satellite SSR}

In this study, we used the following satellite-based SSR data records:

1. CLARA-A2 (CM SAF cLoud, Albedo and surface RAdiation dataset from AVHRR data-Edition 2; doi:10.5676/EUM_SAF_CM/CLARA_AVHRR/V002), a data record based on measurements by the AVHRR sensor onboard a series of polar-orbiting satellites

2. SARAH-2 (Surface Radiation Data Set-Heliosat (SARAH)-Edition 2; doi:10.5676/EUM_SAF_CM/SARAH/V002), a data record derived from satellite-observations of the visible channels of the Meteosat Visible Infra-Red Imager (MVIRI) and the Spinning Enhanced Visible and Infrared Imager (SEVIRI) instruments onboard the geostationary Meteosat satellites

Both data records cover more than 30 years, from the early 1980s up to 2015, and have been produced by EUMETSAT's CM SAF project. Note, however, that we here focus on the period 2003-2013 (see Section 2.5).

Riihelä et al. [10] found-using a previous version of these data records (i.e., SARAH-v001 and CLARA-A1) - that both CLARA and SARAH are capable of estimating the monthly mean SSR with an accuracy better than $10 \mathrm{~W} / \mathrm{m}^{2}$, when compared to ground-based measurements in Sweden and Finland. Another finding of [10] is of particular interest for the present study: they showed, that CLARA in general shows higher SSR values over the Baltic Sea than SARAH, and that CLARA is in better agreement with the ground-based measurements at Utö in the Finnish archipelago.

The CLARA-A2 data record and underlying algorithms are discussed by Karlsson et al. [11] and references therein. The update to version CLARA-A2 included major efforts to correct and homogenize the original satellite radiances measured by the AVHRR instruments. As regards the SSR record, the update substantially improved the spatial coverage. In CLARA-A2, SSR estimates are unavailable only over snow-covered surfaces. Monthly and daily SSR values are available on a regular $0.25^{\circ} \times 0.25^{\circ}$ global latitude-longitude grid 
The SARAH-2 data record and its algorithms are comprehensively presented in EUMETSAT's Algorithm Theoretical Baseline Document [12]. The update to version SARAH-2 included further improvements to the homogeneity of the data record, empirical correction of view-angle dependency of the cloud albedo and adjustment of the water vapour column based on surface elevation. The SARAH-2 products are available as monthly, daily, and $30 \mathrm{~min}$ values on a regular $0.05^{\circ} \times 0.05^{\circ}$ latitude-longitude grid. Note, however, that SARAH- 2 is based on geostationary satellite measurements and therefore does not provide global coverage. The SARAH-2 SSR data, for example, leaves large parts of central and northern Finland uncovered (see, e.g., Figure 3-3 in [12]).

In this study, we used monthly values of the SSR as provided by CLARA-A2 and SARAH-2. In addition to the real-sky estimate of the SSR, both data sets also provide a clear-sky counterpart representing the SSR under the same atmospheric conditions, but assuming cloudless skies.

\subsection{Coastline Information}

The Global Self-consistent Hierarchical High-resolution Geography (GSHHG) database [13,14] contains coastline information constructed from hierarchically arranged closed polygons. The data are available in five different resolutions ranging from crude to full. In this study, we used the low resolution data, version 2.3.5 of GSHHG with some further modifications as explained in Section 2.4.

\subsection{Ground-Based Pyranometer Measurements}

Finally, we also used pyranometer measurements of the SSR (global radiation) of the Finnish and Swedish networks as a reference to which the satellite-retreived results were compared. The stations, listed in Table 1, are operated by the Swedish Meteorological and Hydrological Institute and the Finnish Meteorological Institute. The same stations were included also in a previous study by Riihelä et al. [10], where more details on the instruments used and measurement data can be found.

Table 1. Solar radiation measurement stations included in this study arranged according to their distance to the coastline. Negative distances indicate locations off-shore.

\begin{tabular}{lccc}
\hline Station & Distance $[\mathbf{k m}]$ & Latitude $\left[{ }^{\circ} \mathbf{N}\right]$ & Longitude $\left[{ }^{\circ} \mathbf{E}\right]$ \\
\hline Visby & -94 & 57.673 & 18.345 \\
Utö & -80 & 59.784 & 21.368 \\
Svenska Högarna & -41 & 59.442 & 19.502 \\
Karlstad & -2 & 59.359 & 13.427 \\
Luleå & 1 & 65.544 & 22.111 \\
Göteborg & 3 & 57.688 & 11.980 \\
Helsinki-Kumpula & 3 & 60.203 & 24.961 \\
Stockholm & 4 & 59.353 & 18.063 \\
Umeå & 5 & 63.811 & 20.240 \\
Norrköping & 7 & 58.582 & 16.148 \\
Lund & 10 & 55.714 & 13.212 \\
Helsinki-Vantaa & 11 & 60.327 & 24.957 \\
Jokioinen & 54 & 60.814 & 23.498 \\
Växjö & 84 & 56.927 & 14.731 \\
Borlänge & 98 & 50.488 & 15.430 \\
\hline
\end{tabular}

\subsection{Distance to the Coastline}

In order to scrutinize the land-sea contrast in the climatological SSR, we analyzed the behaviour of the climatological mean SSR as a function of the distance to the coastline. Figure 1 shows the region included in our analysis and the calculated distance to the coastline (see below for information on how the coastline is defined). The measurement stations in Finland and Sweden included in this study are shown as black filled squares. 


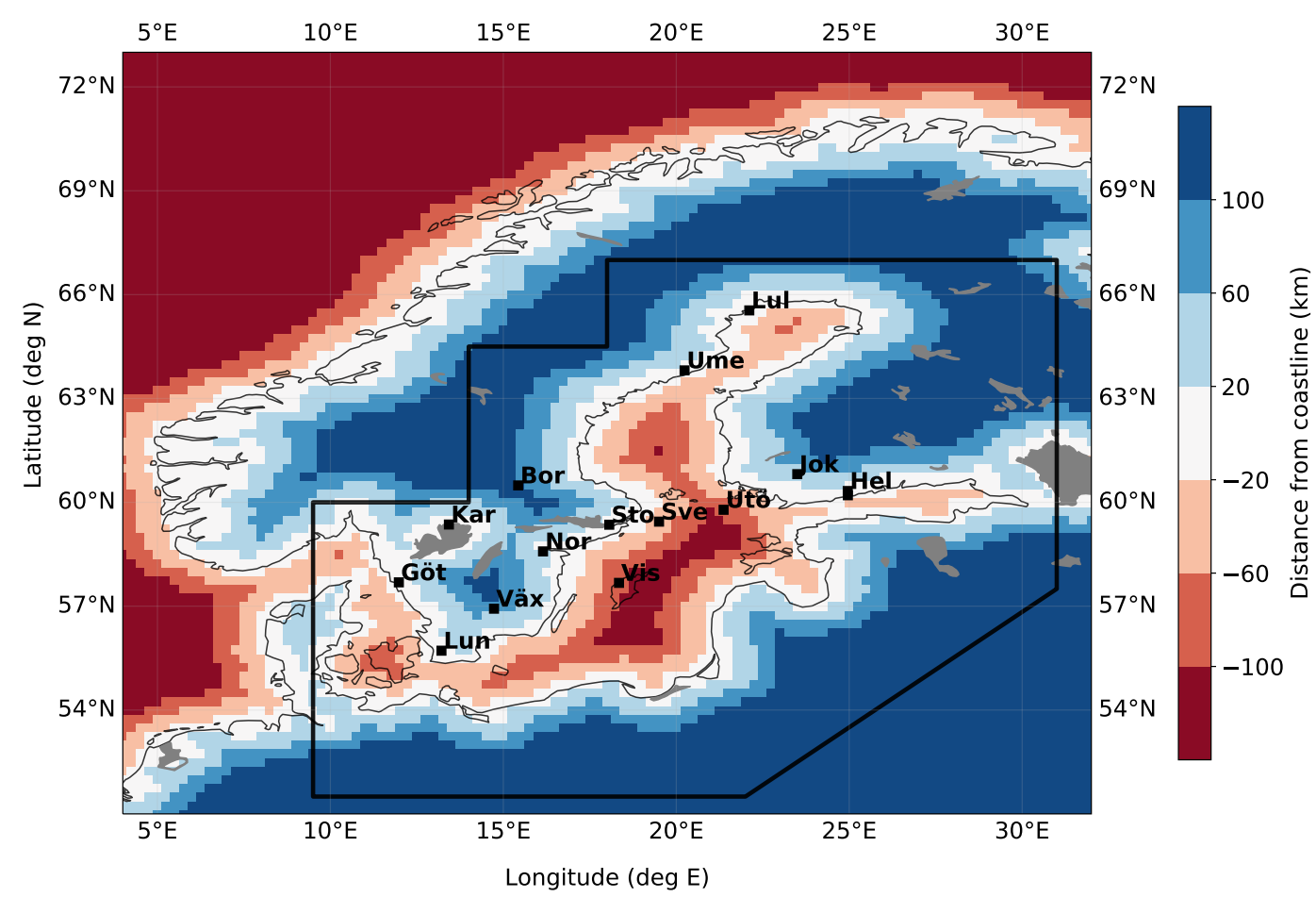

Figure 1. Map of the Baltic region included in this study, bounded by the black line. The color scale indicates the distance to the coastline of the CLARA satellite grid and the black filled squares represent the ground-based measurement stations.

The distance between the center of the satellite grid box and the coastline was calculated for both CLARA-A2 and SARAH-2 as well as for the ground-based measurement stations (see Figure 1 and Table 1). This was done using the haversine formula for the distance along a great circle on a spherical surface. For this, we used a slightly modified version of the low resolution GSHHG database. Our aim here was to obtain an appropriate level of detail in the coastline information, considering the resolution of the satellite data records and the expected distance over which a coastline gradient in the SSR climate can be seen. We wanted to avoid a too high level of detail, which may cause ambiguities in the interpretation of the coastline, in particular, in highly heterogeneous regions.

Starting from the low resolution GSHHG data, we decreased the distance between adjacent points by iteratively adding a point, positioned at the midpoint between the two neighboring points, until the distance between adjacent points became less than $5 \mathrm{~km}$. We also excluded some lakes and islands from our analysis by including only polygons with an area larger than 0.8 square degrees and an area to circumference ratio larger than 0.21 degrees.

The resulting coastline information for the Baltic region is indicated by the distance to the coastline shown in Figure 1. It can be seen, for example, that the islands of Gotland and Själland are here interpreted as sea, which is also the case for Åland as well as other islands of the Baltic. Because of the discreteness of the coastline data used, the calculated distance to the coastline may have an error up to $2.5 \mathrm{~km}$, with additional uncertainty introduced by differences between the true coastline with all its detail and the coastline as represented by our version of the GSHHG data.

\subsection{Period of Analysis}

Riihelä et al. [10] showed that the CLARA satellite SSR record shows better performance as compared with ground-based measurements during the more recent period, when a higher number of polar orbiting satellite overpasses are available for each day. Furthermore, Müller et al. [15] argued that only 10 recent years should be used when estimating the solar energy resource. For these 
reasons, and since ground-based pyranometer measurements from the Finnish and Swedish networks were readily available up to the year 2013 (based on [10]), we have here chosen to focus on the period 2003-2013.

\section{Results}

From the satellite cloud climatology of Karlsson [6], it appears that the strongest land-sea contrast in clouds and solar radiation prevails during summer. While it can be noted that the months May-July exhibit the highest solar radiation, and hence corresponds to 'summer' in terms of the solar radiation climate of this region (e.g., [16]), we here choose to use the standard definitions of seasons in our analysis. This means that December-February (DJF) corresponds to winter, March-May (MAM) to spring, June-August (JJA) to summer, and September-November (SON) to autumn.

Figure 2 shows the summer SSR (surface solar radiation) corresponding to five example transects in various parts of the Baltic. The data here are from CLARA-A2 and the location of the transects have been chosen to correspond to areas which are archipelago-free or at most exhibit a shallow archipelago. Palanga (Lithuania) has the highest SSR of the locations shown, while Haparanda (Sweden) has the lowest. Interestingly, all five transects exhibit a similar gradient in the SSR, decreasing from off-shore locations toward inland. Note that the transect of Gdansk (Poland) is to some extent almost parallel with the true coastline. This may have an influence on the behavior of the SSR close to the coast, where the first satellite grid box off-shore (at around $-5 \mathrm{~km}$ ) exhibits a relatively low SSR value.
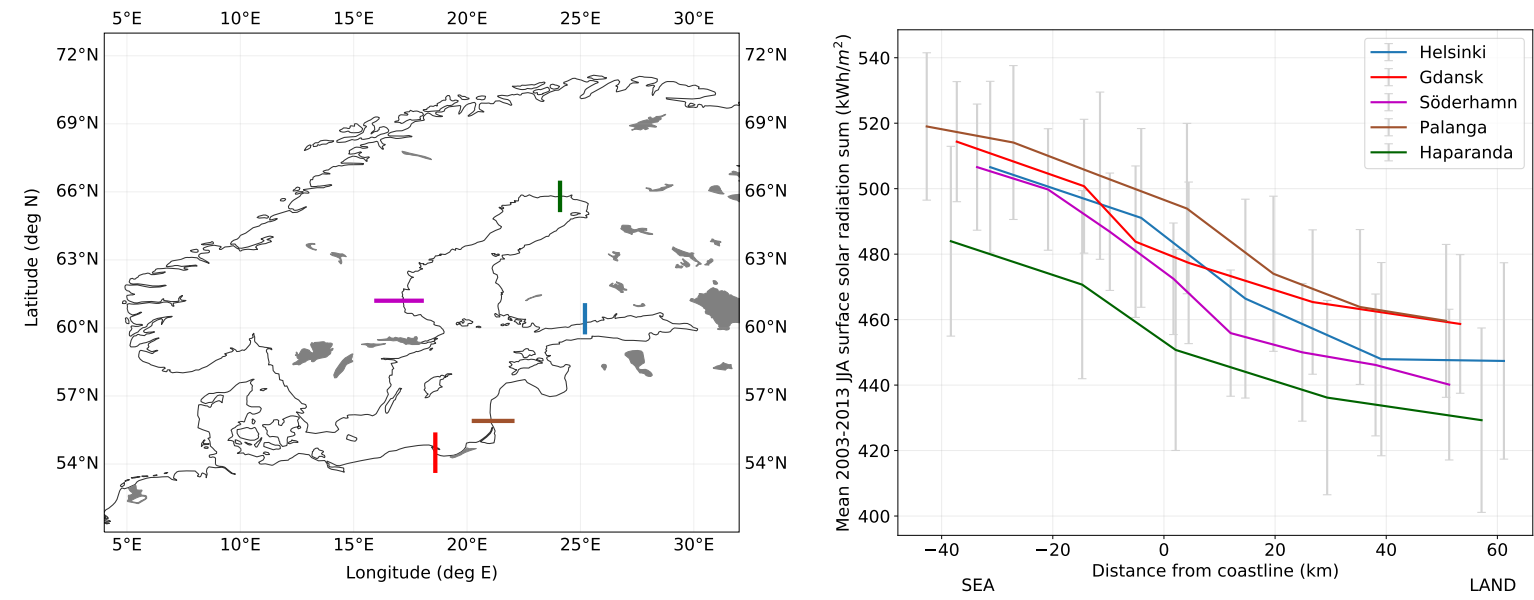

Figure 2. (left) Map showing the location of the transects for which (right) the climatological summer (JJA) SSR according to CLARA-A2 is presented as a function of distance to the coastline. The light grey error bars indicate the standard deviation of the annual summer values.

Figure 3 shows the seasonally averaged SSR for the Baltic region over the period 2003-2013 as a function of distance to the coastline. The figure shows both the SSR based on the two satellite records and as depicted by ground-based pyranometer measurements. Here, the data have been arranged according to the distance to the coastline into the following bins: $\pm 5 \mathrm{~km}, 5-15 \mathrm{~km}, 15-25 \mathrm{~km}$, and so on. The standard deviation of the satellite-based SSR shown in the figure is the median of the standard deviation over the grid boxes at the distance of interest. Similarly, when more than one ground-based measurement station is included in a specific distance bin, the standard deviation is presented as the median of the standard deviation over the stations of interest.

Table 2 shows the average SSR $20 \mathrm{~km}$ out on the sea $\left(\mathrm{SSR}_{-20 \mathrm{~km}}\right)$, at the coastline $\left(\mathrm{SSR}_{0 \mathrm{~km}}\right)$, and $20 \mathrm{~km}$ inland $\left(\mathrm{SSR}_{+20 \mathrm{~km}}\right)$ together with the difference in the SSR between the sea and the land expressed as $\Delta S S R_{ \pm 20 \mathrm{~km}}=\left(\mathrm{SSR}_{-20 \mathrm{~km}}-\mathrm{SSR}_{+20 \mathrm{~km}}\right) / \mathrm{SSR}_{0 \mathrm{~km}} \times 100 \%$. 


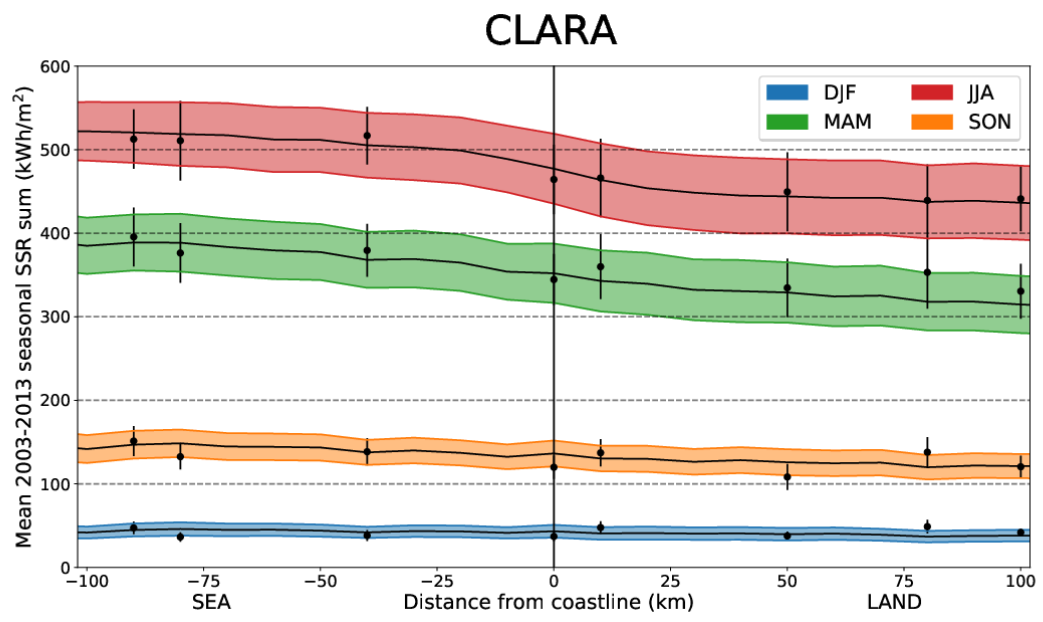

\section{SARAH}

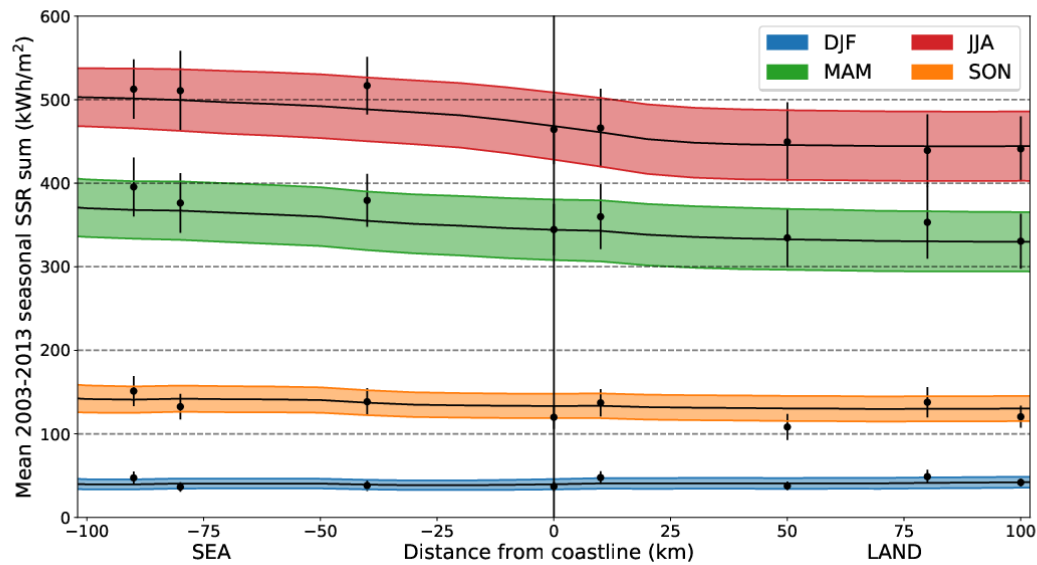

Figure 3. Climatological average (solid line) and standard deviation (colored shading) of the SSR for each season as a function of distance to the coastline for CLARA-A2 (upper panel) and SARAH-2 (lower panel). Ground-based pyranometer measurements of the SSR are shown as black filled circles with corresponding error bars denoting the standard deviation. See text for details.

Table 2. Comparison of the climatological SSR at $20 \mathrm{~km}$ out on the sea, at the coastline, and $20 \mathrm{~km}$ inland according to CLARA-A2 and SARAH-2.

\begin{tabular}{lcccccccc}
\hline & \multicolumn{2}{c}{$\mathbf{S S R}_{\mathbf{2 0 k m}}\left[\mathbf{k W h} / \mathbf{m}^{\mathbf{2}}\right]$} & \multicolumn{2}{c}{$\mathbf{S S R}_{\mathbf{0 k m}^{2}}$} & \multicolumn{2}{c}{$\mathbf{S S R}_{+\mathbf{2 0 k m}}$} & \multicolumn{2}{c}{$\boldsymbol{\Delta \mathbf { S S R } _ { \pm \mathbf { 2 0 k } } [ \% ]}$} \\
& CLARA & SARAH & CLARA & SARAH & CLARA & SARAH & CLARA & SARAH \\
\hline DJF & 43.3 & 38.5 & 42.4 & 39.8 & 41.2 & 40.6 & 4.8 & -5.3 \\
MAM & 368.2 & 349.0 & 351.0 & 344.4 & 339.0 & 338.3 & 8.3 & 3.1 \\
JJA & 499.1 & 481.1 & 476.0 & 468.2 & 453.2 & 452.6 & 9.6 & 6.1 \\
SON & 137.5 & 134.2 & 134.6 & 133.5 & 129.9 & 131.9 & 5.6 & 1.7 \\
YEAR & 1042.0 & 997.0 & 998.3 & 980.1 & 957.8 & 957.9 & 8.4 & 4.0 \\
\hline
\end{tabular}

Both satellite data records exhibit a land-sea contrast in the SSR, which is strongest during the summer period (JJA). Furthermore, springtime (MAM) SSR is higher over the seas than over land. In fact, a separate inspection of individual months reveals that the land-sea contrast in the SSR is strongest for the months May-July, hence coinciding with the months showing the highest climatological SSR. In autumn (SON), there is still a small distinguishable gradient in the SSR over the coastline in the CLARA-A2 data record, while SARAH-2 shows a rather flat behavior. In winter (DJF), SARAH-2 shows a slightly reversed gradient, with somewhat lower SSR over the sea than over land 
(see Table 2). We note, however, that winter time SSR from both SARAH-2 and CLARA-A2 suffer from larger uncertanties due to low sun and possibly snow-covered surfaces.

From Figure 3, it can be further noted, that while both satellite data records show reasonable agreement with the ground-based pyranometer measurements, the spring and summer time land-sea contrast in the SSR is better depicted in CLARA-A2. Both CLARA-A2 and the ground-based SSR measurements exhibit a somewhat stronger land-sea contrast than SARAH-2.

The Cloud Modification Factor (CMF), also referred to as the clear sky index, is a measure of the attenuating effect of clouds on solar radiation [17]. It is generally defined as the ratio of the SSR under all-sky conditions to that for otherwise the same conditions, but with a cloudless sky [18]. Both satellite data records enable the calculation of the CMF, since they provide, in addition to the real-sky estimate of the SSR, a clear-sky counterpart representing the SSR under cloudless skies. Figure 4 shows the monthly CMF of CLARA-A2 and SARAH-2, respectively. The CMF shows a rather similar land-sea contrast as the climatological SSR, with values decreasing from off-shore toward inland areas. Comparing Figure 4 with Figure 3 and Table 2 further reveals an approximate quantitative agreement between the behavior of the CMF and the SSR, supporting the straightforward hypothesis that most of the SSR gradient is caused by clouds. This conclusion is further corroborated by the results of Karlsson [6], who studied the diurnal behavior of the cloudiness in the Baltic area. He found a pronounced diurnal cycle over land during the summer (June-August), with maximum cloudiness in the afternoon. As discussed in the introduction, this indicates that convective clouds forming over the inland areas during the summer part of the year play an important role in the Baltic cloud climate. Similar conclusions can further be drawn indirectly from thunderstorm and lightning climatologies [19,20], showing significant land-sea contrast as well.
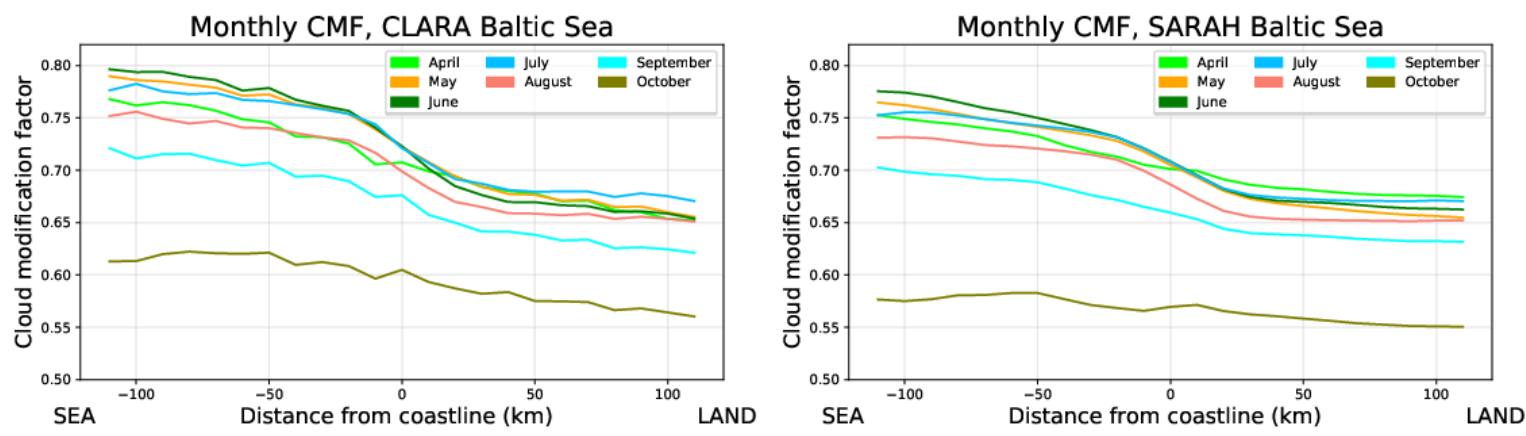

Figure 4. Climatological monthly Cloud Modification Factor (CMF) as a function of distance to the coastline for CLARA-A2 (left panel) and SARAH-2 (right panel).

\section{Discussion}

In this paper, we have studied the climatological behavior of the surface solar radiation (SSR). More specifically, we have used two satellite climate data records, CLARA-A2 and SARAH-2, together with ground-based pyranometer measurements of the SSR to study the land-sea contrast in the climatological SSR over the Baltic area. The results show that off-shore locations on average receive higher SSR than inland areas, in particular during the summer half of the year. For CLARA-A2, which shows better agreement with ground-based measurements, the annual SSR is $8 \%$ higher $20 \mathrm{~km}$ off the coastline than $20 \mathrm{~km}$ inland. SARAH-2 exhibits a smaller difference of $4 \%$. We also show that the observed land-sea contrast in the SSR corresponds closely to the behavior of clouds.

The climatological SSR, a measure of the solar radiation received at a horizontal surface, is an important indicator of the solar energy production potential. As regards photovoltaic (PV) electricity production, however, also the temperature plays a role. The relative efficiency of PV cells typically decreases by $0.5 \%$ for $1{ }^{\circ} \mathrm{C}$ increase in the cell temperature [21]. As temperatures of off-shore and coastal locations are typically cooler than those observed inland during the summer period in the 
Baltic, these regions will gain an additional advantage through the temperature effect of PV cells. Quantification of this temperature effect is, however, left for future work.

An interesting question that remains is why CLARA-A2 shows better agreement than SARAH-2 with pyranometer measurements of the SSR in terms of the land-sea contrast. Although further studies are needed to understand the differences between CLARA-A2 and SARAH-2 in this context, the differences are likely linked to satellite observing geometry and retrieval algorithms. The comparably large viewing angles of the geostationary satellite, for example, require corrections to account for overestimation of the cloud optical thickness, in particular under broken cloud conditions. Such a correction has been applied in SARAH-2, however, a systematic underestimation of the SSR due to viewing geometry cannot be ruled out. As clouds behave differently over sea than over land (as shown in this paper), such an underestimation could have bearing on the results of the present study.

Another factor which may be of relevance relates to assumptions regarding the cloud transmissivity, which is one of the key parameters that determine the SSR. In the case of CLARA-A2, the cloud transmissivity is derived using the reflected top-of-the-atmosphere shortwave flux estimated from the satellite radiance measurements considering auxiliary information (e.g., surface albedo). For SARAH-2, the effective cloud albedo is estimated from the contrast of the cloud reflectivity to the clear-sky reflectivity, which might be larger over sea than over land (even for clouds of similar properties). Furthermore, the estimation of the shortwave reflected flux and the assignment to the cloud transmissivity in the CLARA-A2 algorithm depends also on the surface albedo and other local parameters. For both algorithms used here, effects induced by land-sea contrasts cannot be ruled out. The present study indicates that those effects that smoothen the land-sea contrast in SSR are smaller in CLARA-A2 than in SARAH-2, at least for the region studied, located at comparably high latitudes.

Author Contributions: A.V.L. designed the study and wrote the majority of the manuscript; A.H. and A.R. performed the analysis and contributed to the design of the study and writing of the manuscript; T.C., J.T. and R.M. contributed with ground-based and satellite data expertize and took part in writing of the manuscript. All authors have read and agreed to the published version of the manuscript.

Funding: This research was initially funded by Academy of Finland, decision 284536, and finalized through funding by the Strategic Research Council of Academy of Finland, decision 314167.

Acknowledgments: We thank EUMETSAT's CMSAF project for providing the satellite-based SSR data used in this study.

Conflicts of Interest: The authors declare no conflict of interest.

\section{References}

1. Rossow, W.; Schiffer, R. Advances in understanding clouds from ISCCP. Bull. Am. Meteorl. Soc. 1999, 80, 2261-2284. [CrossRef]

2. Stubenrauch, C.J.; Chedin, A.; Rädel, G.; Scott, N.A.; Serrar, S. Cloud Properties and Their Seasonal and Diurnal Variability from TOVS Path-B. J. Clim. 2006, 19, 5531-5553. [CrossRef]

3. Hahn, C.; Warren, S. A Gridded Climatology of Clouds over Land (1971-96) and Ocean (1954-97) from Surface Observations Worldwide; Technical Report Numeric Data Product NDP-026E; Carbon Dioxide Information Analysis Center, Oak Ridge National Laboratory: Oak Ridge, TN, USA, 2007. [CrossRef]

4. Ångström, A. Solstrålning Och Ljus På Den Svenska Västkusten; Lundbergs Boktryckeri: Göteborg, Sweden, 1928.

5. Lunelund, H. Über die Sonnenscheindauer in Finnland. Soc. Scient. Fenn. Comm. Phys. Math. 1941, XI, 1-14.

6. Karlsson, K. A 10 year cloud climatology over Scandinavia derived from NOAA advanced very high resolution radiometer imagery. Int. J. Climatol. 2003, 23, 1023-1044.10.1002/joc.916. [CrossRef]

7. Persson, T. Solar radiation climate in Sweden. Phys. Chem. Earth Part B Hydrol. Ocean. Atmos. 1999, 24, 275-279. [CrossRef]

8. Posselt, R.; Mueller, R.; Stöckli, R.; Trentmann, J. Remote sensing of solar surface radiation for climate monitoring-The CM-SAF retrieval in international comparison. Remote Sens. Environ. 2012, 118, 186-198. [CrossRef] 
9. Šúri, M.; Huld, T.A.; Dunlop, E.D. PV-GIS: A web-based solar radiation database for the calculation of PV potential in Europe. Int. J. Sustain. Energy 2005, 24, 55-67. [CrossRef]

10. Riihelä, A.; Carlund, T.; Trentmann, J.; Müller, R.; Lindfors, A.V. Validation of CM SAF Surface Solar Radiation Datasets over Finland and Sweden. Remote Sens. 2015, 7, 6663-6682. [CrossRef]

11. Karlsson, K.G.; Anttila, K.; Trentmann, J.; Stengel, M.; Fokke Meirink, J.; Devasthale, A.; Hanschmann, T.; Kothe, S.; Jääskeläinen, E.; Sedlar, J.; et al. CLARA-A2: The second edition of the CM SAF cloud and radiation data record from 34 years of global AVHRR data. Atmos. Chem. Phys. 2017, 17, 5809-5828. [CrossRef]

12. Trentmann, J.; Pfeifroth, U. Algorithm Theoretical Baseline Document, Meteosat Solar Surface Radiation and Effective Cloud Albedo, Climate Data Records—Heliosat, SARAH-2; Technical Report Issue 2.2; EUMETSAT: Darmstadt, Germany, 2017.

13. Wessel, P.; Smith, W. A global, self-consistent, hierarchical, high-resolution shoreline database. J. Geophys. Res. Solid Earth 1996, 101, 8741-8743.10.1029/96JB00104. [CrossRef]

14. GSHHG. Global Self-Consistent Hierarchical High-Resolution Geography (GSHHG). Available online: http:/ / www.soest.hawaii.edu/pwessel/gshhg/index.html (accessed on 16 October 2020).

15. Müller, B.; Wild, M.; Driesse, A.; Behrens, K. Rethinking solar resource assessments in the context of global dimming and brightening. Sol. Energy 2014, 99, 272-282. [CrossRef]

16. Tuononen, M.; O'Connor, E.J.; Sinclair, V.A. Evaluating solar radiation forecast uncertainty. Atmos. Chem. Phys. 2019, 19, 1985-2000. [CrossRef]

17. Calbo, J.; Pages, D.; Gonzalez, J.A. Empirical studies of cloud effects on UV radiation: A review. Rev. Geophys. 2005, 43. [CrossRef]

18. Lindfors, A.; Arola, A. On the wavelength-dependent attenuation of UV radiation by clouds. Geophys. Res. Lett. 2008, 35. [CrossRef]

19. Mäkelä, A.; Enno, S.E.; Haapalainen, J. Nordic Lightning Information System: Thunderstorm climate of Northern Europe for the period 2002-2011. Atmos. Res. 2014, 139, 46-61. [CrossRef]

20. Taszarek, M.; Allen, J.; Pucik, T.; Groenemeijer, P.; Czernecki, B.; Kolendowicz, L.; Lagouvardos, K.; Kotroni, V.; Schulz, W. A Climatology of Thunderstorms across Europe from a Synthesis of Multiple Data Sources. J. Clim. 2019, 32, 1813-1837. [CrossRef]

21. Radziemska, E. The effect of temperature on the power drop in crystalline silicon solar cells. Renew. Energy 2003, 28, 1-12. [CrossRef]

Publisher's Note: MDPI stays neutral with regard to jurisdictional claims in published maps and institutional affiliations.

(c) 2020 by the authors. Licensee MDPI, Basel, Switzerland. This article is an open access article distributed under the terms and conditions of the Creative Commons Attribution (CC BY) license (http:/ / creativecommons.org/licenses/by/4.0/). 